\title{
Introduction to Special Section on Marriage and Family Therapy in China
}

\author{
China Rising: Marriage and Family Therapy in the Middle Kingdom
}

\author{
John K. Miller
}

Published online: 7 May 2014

(C) Springer Science+Business Media New York 2014

To know that we know what we know, and that we do not know what we do not know, that is true knowledge.-Confucius

My first visit to China was 10 years ago when I was asked to join a delegation of family therapists and professors from the West who were invited to travel the country and visit the leading family therapy university, research, and clinical centers. We traveled to China in the spirit of intercultural scholarly exchange. At the time there were only a few university-based family therapy programs and a handful of family therapy clinics for us to visit. Having been raised during a period when there was limited interaction between our countries, many of us Western therapists had little accurate information about what to expect in China. It seemed to me that the more we traveled, interacted, and shared, the more we realized that the story we had been told about China was wrong. Perhaps the most significant misunderstanding about China was that there is a single Chinese culture. In reality, we found that the Chinese culture is a rich mixture of racial and ethnic diversity with five major language families and 56 distinct ethnic groups. And, like in our home countries in the West, we found that the people and culture varied greatly based on region and rural versus urban locations. What we did not know that we did not know, was that there are many stories of China.

It was also clear to us during our journey that something important was happening, and that family therapy (and the general field of counseling/therapy/psychology) was beginning a rapid development in China. Where previously the government had discouraged Western therapy as a capitalist

\footnotetext{
J. K. Miller ( $($ )

Nova Southeastern University, 3301 College Avenue, Fort Lauderdale, FL 33314, USA

e-mail: jm2790@nova.edu
}

based pseudo-science, the trend now was to encourage opening up to the West and exploring therapeutic ways of helping people. Given the collectivist nature of the Chinese culture, orientations of mental health that took into account the concept of interconnectedness seemed an especially good fit. With the cultural heritage of "filial piety" (孝 or xiào, meaning a virtue of respect for one's parents and ancestors) relational and family orientations seemed to make the best sense for addressing problems in the Chinese context. Indeed over the past 10 years we have witnessed an explosion of activity in the field of family therapy in China. Where there were once only a few graduate programs in family therapy, there are now dozens. Where there were only a few family therapy clinics, there are now hundreds. Where there were only a hundred or so therapists, there are now thousands (or state the closer approximation). The development of family therapy in China has also been encouraged by the government's recognition of the tremendous social burden caused by untreated mental health issues, as well as the rapidly developing Chinese economy.

While it is clear that some form of indigenous therapies have likely existed in China for thousands of years, what is commonly thought of as therapy today in China is the product of collaborations with Chinese and Western scholars (Miller and Fang 2012). As family therapy has continued to develop in China, several questions have emerged among the scholarly community. What are some of the main therapy issues that arise in China and how are they unique to the Chinese context? What are the best ways to utilize Western practices while also honoring indigenous Chinese ways of knowing and healing? What are some examples of successful Chinese family therapies, and what can we learn from these examples as we look to the future?

In 2012 when Dr. Russell Crane, Editor of Contemporary Family Therapy, asked me to serve as the editor for 
this special section on "Marriage and Family Therapy in China" our focus was to address some of these questions as well as to encourage the family therapy scholars of China to share with the world their ideas and practices. The following special section features some of the exciting work of these pioneers of family therapy in China, discussing such topics as the profile of the Chinese therapist, factors that affect therapeutic alliance, comparisons between Chinese and German therapists, the role of family functioning and social support with depressed clients in China, and a unique systemic approach to helping a family with a member with adult mental illness. These articles give us a unique perspective on the important work occurring in
Chinese family therapy, as well as an indication of what the future holds. I hope the reader might find, as we did during our delegation across China a decade ago, that there is more to know about China (and the practice of therapy) than we thought we knew.

\section{Reference}

Miller, J. K., \& Fang, X. (2012). Marriage and family therapy in the People's Republic of China: Current issues and challenges. Journal of Family Psychotherapy, 23, 173-183. 